\title{
Overexpression of TGF $\beta 1$ in murine mesenchymal stem cells improves lung inflammation by impacting the Th17/Treg balance in LPS-induced ARDS mice
}

Jianxiao Chen, Xiwen Zhang, Jianfeng Xie, Ming Xue, Ling Liu, Yi Yang and Haibo Qiu*

\section{Abstract}

Background: $T$ helper 17 cells (Th17)/regulatory T cells (Treg), as subtypes 0 CD4 ${ }^{+}$D cells, play an important role in the inflammatory response of acute respiratory distress syndron. $A$ P fowever, there is still a lack of effective methods to regulate the differentiation balance of Th17/Treg. was proven that mesenchymal stem cells (MSCs) could regulate the differentiation of $\mathrm{CD}^{+} \mathrm{T}$ cell the, nechanism is still unclear. TGF $\beta 1$, a paracrine cytokine of MSCs, could also regulate the differentiation $8,17 / 7$ reg but is lowly expressed in MSCs. Therefore, mouse MSCs (mMSCs) overexpressing TGF $\beta 1$ were onstructed by lentivirus transduction and intratracheally transplanted into LPS-induced ARDS mice ili study. The aim of this study was to evaluate the therapeutic effects of mMSCs overexpressing TGEP on in mmation and immunoregulation by impacting the Th17/Treg balance in LPS-induced ARDS mice

Methods: mMSCs overexpressing TGF $\beta 1$ were en tr ted using lentiviral vectors. Then, mouse bone-marrowderived MSCs (mBM-MSC) and MBM-MSC-TGPS ( $m$-MsC overexpressing TGF $\beta 1$ ) were transplanted intratracheally into ARDS mice induced by 4 , polysac,naride. At 3 and 7 days after transplantation, the mice were sacrificed, and the homing of thermiMSC as, assayed by ex vivo optical imaging. The relative numbers of Th17 and Treg in the lungs and sple ens of mice, vere detected by FCM. IL-17A and IL-10 levels in the lungs of mice were analysed by western blc Permeäbility and inflammatory cytokines were evaluated by analysing the protein concentration of BALF using SA Aistopathology of the lungs was assessed by haematoxylin and eosin staining and lung injury scori Alveolar lung fibrosis was assessed by Masson's trichrome staining and Ashcroft scoring. The mortality of ARDS $m /$ e vas followed until 7 days after transplantation.

Results: The transdu <tio, efficiencies mediated by the lentiviral vectors ranged from 82.3 to $88.6 \%$.

Overexpressing TGF, in $\quad$ the proliferation of mMSCs during days $5-7(p<0.05)$ but had no effect on mMSC differen ation o vigration $(p>0.05)$. Compared to that in the LPS + mBM-MSC-NC group mice, engraftmen+ $\mathrm{O}$ MSCs d verexpressing TGF $\beta 1$ led to much more differentiation of T cells into Th17 or Treg $(p<0.05)$ improve armeability of injured lungs $(p<0.05)$ and ameliorative histopathology of lung tissue in (Contin d on next page)

(c) The Author(s). 2020 Open Access This article is licensed under a Creative Commons Attribution 4.0 International License which permits use, sharing, adaptation, distribution and reproduction in any medium or format, as long as you give appropriate credit to the original author(s) and the source, provide a link to the Creative Commons licence, and indicate if changes were made. The images or other third party material in this article are included in the article's Creative Commons licence, unless indicated otherwise in a credit line to the material. If material is not included in the article's Creative Commons licence and your intended use is not permitted by statutory regulation or exceeds the permitted use, you will need to obtain permission directly from the copyright holder. To view a copy of this licence, visit http://creativecommons.org/licenses/by/4.0/ The Creative Commons Public Domain Dedication waiver (http://creativecommons.org/publicdomain/zero/1.0/) applies to the data made available in this article, unless otherwise stated in a credit line to the data. 
(Continued from previous page)

ARDS mice $(p<0.05)$. Moreover, IL-17A content was also decreased while IL-10 content was increased in the

LPS + mBM-MSC-TGF 1 group compared with those in the LPS + mBM-MSC-NC group $(p<0.05)$. Finally, mMSCs

overexpressing TGF $\beta 1$ did not aggravate lung fibrosis in ARDS mice $(p>0.05)$.

Conclusion: MSCS overexpressing TGF $\beta 1$ could regulate lung inflammation and attenuate lung injuries by modulating the imbalance of Th17/Treg in the lungs of ARDS mice.

Keywords: Acute respiratory distress syndrome, Mesenchymal stem cells, TGF $\beta 1$, Th17/Treg

\section{Background}

Acute respiratory distress syndrome (ARDS), which was initially defined 52 years ago as a multifactorial syndrome of severe lung injury [1], is characterised by hypoxaemia, loss of lung compliance, and pulmonary oedema, which can in some instances progress to multiple organ failure [2]. ARDS can develop in response to multiple predisposing factors, including pneumonia, systemic infection, and major surgery or multiple traumas [3], and results in death in $30-45 \%$ of cases [4].

In the past 50 years, considerable progress has been made in understanding the pathology of ARDS, and the development of ARDS is strongly associated with a disordered immune response in the lung [5]. In previous studies, $\mathrm{CD}^{+} \mathrm{T}$ cells, as an important component of adaptive immune cells, were significantly activated in the early stage of ARDS and the differentiation of $\mathrm{T}$ helper 17 cells (Th17)/regul ry) T cells (Treg) played an important role in the devel opme of ARDS [5]. Th17 can release many inflammato cytokint that mediate the acute inflammatory response [6. Treg, as important immunosuppressive cells, $\mathrm{c} n$ also be ac, $\mathrm{s}$ vated in ARDS, and the transplantation of reg into an ARDS model mice may reduce the levels of pr flam natory cytokines in the alveoli [7] and inhib meutropnil apoptosis and fibrocyte recruitment [8]. In ad lity che differentiation balance of Th17/Treg is indep endent predictor for 28day mortality in patie wi $\triangle R D S$ [9]. Thus, there is still a lack of effective meth to regulate the differentiation balance of Th1

Our previous stu proved that mesenchymal stem cells (MSCs), with their n, altipotency and immunoregulation propera suld significantly improve inflammation and rep lung iures in ARDS mice [10]. The mechanism of - eir mmunslogical regulation may be related to the n. uraciu of $\mathrm{T}$ cell expansion [11]. It has also been confirm in a recently published study that MSCs could regulate the imbalance of Th17/Treg, which is regulated by antigen-stimulated costimulatory molecules, antigenpresenting cells, cytokines, and intracellular signals [11]. TGF $\beta 1$, an important cytokine that regulates the differentiation of Th17/Treg [12], is expressed at low levels in MSCs, which was proven by our preliminary data. Thus, overexpression of TGF $\beta 1$ is expected to further optimise MSC treatment for immunoregulation.
Therefore, the aim of this study was to valyate the effect of mouse MSCs (mMSCs) verexpress.ng TGF $\beta 1$ on inflammation and immunoreg tion ir. LPS-induced ARDS mice.

\section{Materials and metho}

\section{Cell culture}

mMSCs isolate $\mathrm{h} m$ the bone marrow of C57BL/6 mice (mBM-T 1 urchased from Cyagen Biosciences, Inc. (Guan hou, China), and $293 \mathrm{~T}$ cells were supplied aonbio Biotechnology Co., Ltd. (Nanjing, China). The no A-MSC were identified by detecting cell surface phenotypes and their multipotent potential for aln ntiation along the adipogenic, osteogenic, and hon ogenic lineages as previously described $[13,14]$.

ity er mBM-MSC or $293 \mathrm{~T}$ cells were cultured in a 1:1 m) $x$ of Dulbecco's modified Eagle's medium/nutrient mixture F-12 (DMEM/F12) (Wisent, Inc., St-Bruno, Montreal, Quebec, Canada) containing 10\% FBS (Wisent, Inc.) and $1 \%$ antibiotic-antimycotic (streptomycin, penicillin and amphotericin B; Wisent, Inc.), incubated at $37^{\circ} \mathrm{C}$ in a humidified atmosphere of $5 \% \mathrm{CO}_{2}$ and passaged every 3-4 days by $0.25 \%$ trypsin-ethylenediaminetetraacetic acid (EDTA; Gibco, Carlsbad, CA, USA) when they reached approximately $80 \%$ confluence. Passages between 5 and 10 were used for the experimental protocols.

\section{Recombinant lentivirus vector construction and packaging} The full-length coding sequence (CDS) of mouse TGF $\beta 1$ was transferred into the CMV promoter-dependent lentivirus vector PDS159_pL6.3-CMV-GFPa1-IRES-MCS (Zoonbio Biotechnology Co., Ltd.). Subsequently, the lentivector CL721-pL6.3-CMV-GFPa1-IRES-mus-TGF- $\beta$ (overexpressing TGF $\beta 1$ ), which co-expresses enhanced green fluorescent protein (eGFP) and TGF $\beta 1$, was obtained, and the empty vector CL721-pL6.3-CMV-GFPa1-IRES was used as an empty vector control. Then, the recombinant plasmids CL721-pL6.3-CMV-GFPa1-IRES-mus-TGF- $\beta$ and CL721-pL6.3-CMV-GFPa1-IRES were separately cotransfected with packaging plasmids into $293 \mathrm{~T}$ cells at the indicated concentrations using Lipofectamine 2000 (Invitrogen Life Technologies) according to the manufacturer's instructions, producing the lentivirus LV402-pL6.3-CMVGFPa1-IRES-mus-TGF- $\beta$ and the negative control PDS019. 


\section{Lentiviral vector transduction and eGFP reporter gene detection}

The mBM-MSC $\left(1 \times 10^{6} /\right.$ well seeded in six-well cell culture plates) were transduced with viral supernatant at a multiplicity of infection (MOI) of 160:1 for $24 \mathrm{~h}$. Then, the stable cell lines were harvested after selection using blasticidin (BSD; InvivoGen) at the minimal lethal concentration $(6 \mu \mathrm{g} / \mathrm{mL})$ as previously described [15] and cultured in normal culture medium for 20 passages after transduction. Finally, the transduction efficiency of mBM-MSC and the percentage of eGFP-positive cells were evaluated by fluorescence microscopy and flow cytometry (FCM) analysis using a FACSCalibur flow cytometer (Becton-Dickinson, Franklin Lakes, NJ, USA).

\section{Cell surface phenotype detection}

The cells were also identified by detecting cell surface phenotypes after lentivirus transduction. Fluorescein conjugated monoclonal antibodies, including CD29, CD34, CD44, CD105, and CD45, and the respective isotype controls were purchased from Becton-Dickinson (Franklin Lakes, NJ, USA). FCM analysis was performed with fluorescence-activated cell sorting analysis.

\section{RNA isolation and quantitative real-time PCR (qRT-PCR)}

Total RNA was isolated from the cells and tissues yomg TRIzol reagent (Invitrogen, Austin, TX, USA) ac dir a to the manufacturer's protocol, and the purity $f$ the (260/280 $\mathrm{nm}$ absorbance ratio of 1.8-2.2) w? sessed b) a spectrophotometer (Tecan, Switzerland). everse transcription was completed using a RevertAic First Strand cDNA Synthesis Kit (Thermo cientific) with $1 \mathrm{mg}$ of RNA according to the manufac or's instructions. qRT-PCR was performed usi a CFXy $6^{\text {тм }}$ Real-Time system (Bio-Rad). Relative change, gene expression were normalised to the ession of actin and calculated by the $2(-\Delta \Delta \mathrm{Ct}) \mathrm{me}^{+} \mathrm{d}$. ' ho nrimer sequences used for PCR amplification in on study were designed based on the sequences 0 genon $\mathcal{c}$ clones and are as follows:

\begin{tabular}{|c|c|c|c|}
\hline Gene & & sequence & $\begin{array}{l}\text { PCR amplified } \\
\text { product (bp) }\end{array}$ \\
\hline & & AGGGAAATCGTGCGTGAC-3' & \multirow[t]{2}{*}{195} \\
\hline & & 5'-CCATACCCAAGAAGGAAGGCT-3' & \\
\hline & & 5'-TGTGTCCGTCGTGGATCTGA-3' & \multirow[t]{2}{*}{150} \\
\hline & Reverse & 5'-TTGCTGTTGAAGTCGCAGGAG-3' & \\
\hline \multirow[t]{2}{*}{ TGF $\beta 1$} & Forward & 5'-GACTCTCCACCTGCAAGACC-3' & \multirow[t]{2}{*}{100} \\
\hline & Reverse & 5'-GGACTGGCGAGCCTTAGTTT-3' & \\
\hline \multirow[t]{2}{*}{ Collagen I } & Forward & 5'-GTGTTTCCTGTGCTACTG-3' & \multirow[t]{2}{*}{132} \\
\hline & Reverse & 5'-TCTTTCTCCTCTCTGACC-3' & \\
\hline \multirow[t]{2}{*}{ a-SMA } & Forward & 5'-CCTCGCCTCTACCCCTTA-3' & \multirow[t]{2}{*}{120} \\
\hline & Reverse & 5'-ATTCGCTTGCCTTTGCTT-3' & \\
\hline
\end{tabular}

\section{Western blot analysis}

To evaluate the TGF $\beta 1$ concentration in mBM-MSC, the total cellular protein was extracted by RIPA lysis buffer (Beyotime Institute of Biotechnology, Haimen, China) containing an antiprotease cocktail $(1 \mathrm{mmol} / \mathrm{L}$ PMSF, 1 $\mathrm{mmol} / \mathrm{L} \mathrm{NaF}$ and $1 \mathrm{mmol} / \mathrm{L} \mathrm{Na}_{3} \mathrm{VO}_{4}$; US Biologic- Inc., Swampscott, MA, USA) according to the manufac urer's instructions, quantified by a BCA protein assay kit (b ame) separated by sodium dodecyl sulfate-polyacrylamic sel electrophoresis (SDS-PAGE) (10\%), elec. transfe red to PVDF membranes (Millipore, Bedford, IVA, $\checkmark$ ), and then incubated with primary antibodies against TG $\beta 1$ (1:5000 dilution; Abcam Incorporated, Can ridge, MA) or $\beta$-actin (1:3000 dilution; Abcam Inco rate, nbridge, MA) at $4{ }^{\circ} \mathrm{C}$ overnight. The blot, were shed three times with TBST and then incubre $r$ r $1 \mathrm{~h}$ at, room temperature with goat anti-rabbit IgG conjuga. with horseradish peroxidase (1:5000 dilution Lo bio Biocechnology). Immunoreactive complexes were is by chemiluminescence reagents (Thermo Fisher So tific Inc., Waltham, MA, USA), and immunor o banas were obtained using a chemiluminescence in glr, system (BioshineChemiQ4800 mini; Ouxiang, Sh anghai, China). Finally, the intensity of those Da. was analysed by Image J software (NIH, USA).

\section{te. $n$ concentration in culture medium}

mbM-MSC, mBM-MSC-NC, and mBM-MSC-TGF $\beta 1$ were seeded in a 12 -well plate at a density of $1 \times 10^{5}$ cells per well. After $12 \mathrm{~h}$, the culture medium was changed, and mBM-MSC were cultured in an incubator at $37{ }^{\circ} \mathrm{C}$ and $5 \% \mathrm{CO}_{2}$ for $24 \mathrm{~h}$. The culture medium was then collected, and TGF $\beta 1$ protein levels in the culture medium were quantified using an enzyme-linked immunosorbent assay (ELISA) kit (Abcam, USA) according to the manufacturer's instructions.

\section{Cell proliferation assay}

Cell Counting Kit-8 (CCK-8; Beyotime Institute of Biotechnology, Haimen, China) assays were used to further investigate the effects of overexpressing TGF $\beta 1$ on mBM-MSC proliferation according to the manufacturer's instructions. Briefly, cells were seeded in 96-well plates at $2 \times 10^{3}$ cells per well in $100 \mu \mathrm{L}$ of growth medium. After staining with CCK-8 (10 $\mu \mathrm{L}$ per well), the cells were incubated for $4 \mathrm{~h}$ at $37^{\circ} \mathrm{C}$. Absorbance was assessed at $450 \mathrm{~nm}$ with a microplate reader (Tecan, Switzerland).

\section{Multidifferentiation of mMSCs after gene transduction}

For osteogenic differentiation, the cells were seeded in 6-well plates and cultured in $2 \mathrm{~mL}$ of DMEM/F12 supplemented with 10\% FBS. When the cells reached approximately 80-90\% confluence, they were switched to $\mathrm{C} 57 \mathrm{BL} / 6 \mathrm{mMSC}$ osteogenic differentiation medium (Cyagen Biosciences, Inc., Guangzhou, China) for 2-3 
weeks. Calcium deposition was assessed by staining the cells with $40 \mathrm{mM}$ Alizarin Red S solution at room temperature for $10 \mathrm{~min}$.

For adipocytic differentiation, when reaching confluence, the cells were treated with mMSCs adipogenic differentiation basal medium A (Cyagen Biosciences, Inc., Guangzhou, China) for 3 days, followed by exchange with mMSCs adipogenic differentiation basal medium B (Cyagen Biosciences, Inc., Guangzhou, China) for $24 \mathrm{~h}$ and then switching back to basal medium A. After five to six cycles, the cells were cultured in basal medium B for 3 days until their lipid vacuoles enlarged. To assess the accumulation of neutral lipid vacuoles, the cells were stained with filtered Oil Red $\mathrm{O}$ solution for $10 \mathrm{~min}$ at room temperature, and the incorporated Oil Red $\mathrm{O}$ was extracted by adding $1 \mathrm{~mL}$ of isopropanol to each well at room temperature for $15 \mathrm{~min}$.

For chondrogenic differentiation, $2.5 \times 10^{5}$ cells were centrifuged in a $15 \mathrm{~mL}$ tube at $150 \times g$ for $5 \mathrm{~min}$ to form a pellet. Chondrogenic differentiation was achieved by the three-dimensional culture method and C57BL/6 mMSCs chondrogenic differentiation medium (Cyagen Biosciences, Inc., Guangzhou, China). After 28 days, the pellets were embedded in paraffin and then fixed in dimethylbenzene and ethanol. Five-micrometre sections were cut and stained with Alcian blue to determine the polysaccharide accumulation.

\section{In vitro scratch assay}

The horizontal migration of cells was dete $\mathrm{mL}_{\mathrm{L}}$ by the in vitro scratch assay. Cells were seeded:1 six-weli lure plates. After reaching approximately $100 \%$ confluence, a scratch was made with a $10-\mu \mathrm{L}$ steri pipette tip. Then, the cells were cultured in serum-fre $1 E M / F 12$ for another $12 \mathrm{~h}$. The images of $\mathrm{t}$ ind area were recorded by a light microscone imr diazely after scratching and $12 \mathrm{~h}$ later. The ho zon $1 \mathrm{mig}$ tion ability of the cells was quantified by $m$. ne wound area in each group by Image analysis ftware [13].

\section{Transwel' migration à say}

The ver pigration of cells was determined by the Tr well igration assay. Transwell inserts $(6.5 \mathrm{~mm}$ ame er an $8 \mathrm{~mm}$ pore size; Millipore) that were so ea with $2 \times 10^{4}$ cells in $100 \mu \mathrm{L}$ of serum-free $\mathrm{DM}_{\perp} / \mathrm{F} 12$ were loaded into lower chambers with $600 \mu \mathrm{L}$ of DMEM/F12 supplemented with $10 \%$ FBS. After incubation for $12 \mathrm{~h}$, the cells remaining on the upper surface of the inserts were removed with cotton swabs, and the cells that had migrated to the lower surface were stained with crystal violet (Beyotime Institute of Biotechnology, Haimen, China) for $20 \mathrm{~min}$. The stained cells from four randomly chosen areas were measured under a light microscope [13].

\section{Ethics statement}

All animal experiments in this study were performed in accordance with the Guide for the Care and Use of Laboratory Animals and were approved by the Institutional Animal Care and Use Committee of Southeast University. Wild-type (WT) C57BL/6 mice aged 6-8 weeks were purchased from the I roratory Animal Centre (Shanghai, China). Mice were $h_{t}$ ea in individual microisolator cages under specific path free conditions with free access to water d chov

\section{Murine model of lipopolysaccharid :-induced ay,ute} respiratory distress syndrome

After anaesthetization with int r. roneal injection of pentobarbital at $50 \mathrm{rg} / \mathrm{kg}$, ce, were subjected to intratracheal (i.t.) dh istratio of LPS $(2 \mathrm{mg} / \mathrm{kg}$, Escherichia coli serotype 111:B4; Sigma-Aldrich, St Louis, MO, US a a olved in $20 \mu \mathrm{L}$ of sterile normal saline (NS). Sha o w was performed in a similar manner with the ne volume of only $0.9 \%$ NS instead of LPS. I the nice recovered until fully awake in a $100 \%$ oxygen cri, mber.

\section{Ex imental protocol}

The ice were randomly divided into five groups as oy/s: the control group, mice that received phosphate-buffered saline (PBS) intratracheally $4 \mathrm{~h}$ after 1.t. administration of $0.9 \% \mathrm{NS}$; the ARDS group, mice that received PBS intratracheally $4 \mathrm{~h}$ after LPS challenge; the LPS + mBM-MSC group, mice that received WT mBM-MSC $\left(2 \times 10^{5}\right.$ cells per mouse $)$ intratracheally; the $\mathrm{LPS}+\mathrm{mBM}-\mathrm{MSC}-\mathrm{NC}$ group, mice that received mBMMSC-NC (normal control, $2 \times 10^{5}$ cells per mouse) intratracheally; and the LPS + mBM-MSC-TGF $\beta 1$ group, mice that received $\mathrm{mBM}-\mathrm{MSC}-\mathrm{TGF} \beta 1$ (overexpressing TGF $\beta 1,2 \times 10^{5}$ cells per mouse) intratracheally. The mice were sacrificed at 1,3 , or 7 days after mBM-MSC injection, and the lung lobes were collected for further analysis.

\section{Preparation of lung tissue lymphocytes and flow cytometry analysis}

After the mice were sacrificed, $5 \mathrm{~mL}$ of $\mathrm{PBS} / 0.6 \mathrm{mM}$ EDTA was injected into the right ventricular cannula for lung perfusion. The lung was then isolated from the surrounding tissue and added to medium containing digestive enzymes (RPMI 1640, $20 \mathrm{mM}$ HEPES, 10\% FCS, $175 \mathrm{U} / \mathrm{mL}$ collagenase, $75 \mathrm{U} / \mathrm{mL}$ DNAse I, $0.2 \mathrm{U} /$ $\mathrm{mL}$ pancreatic elastase, $35 \mathrm{U} / \mathrm{mL}$ hyaluronidase, $100 \mathrm{IU} /$ $\mathrm{mL}$ penicillin, and $100 \mathrm{mg} / \mathrm{mL}$ streptomycin) for incubation for $45 \mathrm{~min}$ at $37^{\circ} \mathrm{C}$. The resulting suspension was passed three times through a 19-gauge needle to break up clumps and then through a $40-\mathrm{mm}$ filter to remove debris. The leukocytes were enriched by 
discontinuous Percoll gradient centrifugation and recovered at the interface between $40 \%$ Percoll and 70\% Percoll layers [16].

The following antibodies (Miltenyi, USA) were used for surface and nuclear staining: FITC-labelled anti-CD4, APC-labelled anti-CD25, PE-labelled anti-Foxp3, and PE-labelled anti-RORyt. For the analysis of Treg, cells were incubated with the surface marker antibodies FITC-anti-CD4 and APC-anti-CD25, followed by fixation and permeabilization with Foxp3-staining buffer (Miltenyi) and intracellular staining with PE-labelled anti-Foxp3. To detect the phenotypes of Th17 cells in the lungs, cells were incubated with the surface markers FITC-anti-CD4 and APC-anti-CD25. Then, the cells were fixed and permeabilized using ROR $\gamma$ t-staining buffer (Miltenyi), followed by intracellular staining with PE-labelled anti-ROR $\gamma$ t.

\section{Protein concentration in the lungs and bronchoalveolar lavage fluid}

To analyse the expression of IL-17A, IL-10, and occludin in the lungs after transplantation, total protein lysates were extracted by RIPA lysis buffer (Beyotime) from left lung lobes ( $n=3$ per group at each time-point) and measured by western blot as previously described. The PVDF membranes were incubated with primary antibodies against IL-17) $\mathrm{N}$ : 5000 dilution, Abcam), IL-10 (1:5000 dilution, A an occludin (1:5000 dilution; Abcam), or $\beta$-actin (1,0000 tion; Abcam Incorporated, Cambridge, MA).

Bronchoalveolar lavage fluid (BALF) yas cou ted by flushing $1 \mathrm{~mL}$ of ice-cold PBS back an forth three times through a tracheal cannula as previou described $[14,15]$. After centrifugation at $800 \times g$ for $10 \mathrm{mi}$ tal rotein (TP), albumin (ALB), tumour necrosis tor- $\alpha$ (INF- $\alpha$ ), and IL$1 \beta$ and IL- 6 concentrations in the $B$ were measured by ELISA kits (Cusabio Bi h, Whan, China; Excell Bio, Shanghai, China).

Labelling and t. ing of $m_{c}$ enchymal stem cells WT mBM-MSC, $\mathrm{n}$. Y-MSC-NC, and mBM-MSC-TGF $\beta 1$ were labsiled with $C_{t, 1}$ Vue NIR815 dye (eBioscience Inc., San Dit (. ISA) according to the manufacturer's instrv ins. en, NIR815-labelled cells $\left(5 \times 10^{5}\right.$ cells) were rect $\angle$ admi istered into the trachea of the mice in differe. roupu according to the protocol. After 1, 3, and 7 days post asplantation, three mice at each time point were sacrificed, and ex vivo lungs were imaged using a Maestro in vivo optical imaging system (excitation $=786 \mathrm{~nm}$, emission $=814 \mathrm{~nm}$, and $4000 \mathrm{~ms}$ exposure time; Caliper Life Sciences, MA, Boston, USA) [15, 17]. The autofluorescence spectra were then unmixed based on their spectral patterns using Maestro 2.4 software (Caliper Life Sciences). The fluorescence intensity of the lungs was measured by placing the regions of interest (ROIs) on the lungs, and the signals were analysed based on the total fluorescence counts of the ROIs.

\section{Evaluation of lung oedema}

Lung oedema was evaluated using the ratio of lung wet weight to body weight (LWW/BW), which was measured as previously described [17]. Briefly, the whol no was removed and cleared of all extrapulmonary tissu and the LWW/BW was calculated based on ve values o, the lung wet weight and the body weight (mg/ל

\section{Lung histopathology analysis}

The right lung lobes $(n=3 \pi$ ach ap at each timepoint) were collected an a tixed 4\% paraformaldehyde, embedded in paraff $1, \mathrm{~d}$ sliç $\mathrm{d}$ into $5 \mu \mathrm{m}$ sagittal sections. After staining $w_{1}$ a haematoxylin and eosin staining kit (Bey otın Instituze of Biotechnology, Haimen, China), the sha $\quad \mathrm{n}$ viewed by a pathologist based on ten randomly lected high-power fields $(\times 400)$ in each secti cording to oedema, alveolar and interstitial inflammation, ar eolar and interstitial haemorrhage, atelectasis, and necrosis, which was graded on a 0- to 4-point Sca 0 , no injury; 1 , injury in $25 \%$ of the field; 2 , injury in $50 \%$ the field; 3 , injury in $75 \%$ of the field; and 4 , injury ovghout the entire field). The total lung injury score was calculated as the sum of these scores, which has been described previously $[14,15,17]$.

\section{Lung fibrosis analysis}

The lung sections were stained sequentially with Weigert's iron haematoxylin solution, Biebrich scarletacid fuchsin solution, and aniline blue solution, and a blue signal indicated positive staining for collagen. The criteria of Ashcroft were used [15, 17] to assess lung fibrosis, which was quantified based on the findings in ten randomly selected high-power fields $(\times 400)$ for each slide by histopathologists blinded to the protocol. Collagen-I and $\alpha$-SMA mRNA expression in lung tissues was measured by RT-PCR.

\section{Statistical analysis}

The data are presented as the means \pm standard deviations (SDs). Statistical analyses were performed using SPSS 26.0 (SPSS Inc., Chicago, IL, USA) and GraphPad Prism 8 (GraphPad Software, La Jolla, California USA). Comparisons among multiple groups were performed by one-way ANOVA followed by Bonferroni's post hoc test if the data were normally distributed. Kaplan-Meier curves were used to describe the survival rate of mice in each group, and log-rank tests were performed to analyse the significance of differences. A $p$ value $<0.05$ was considered statistically significant. 


\section{Results}

The efficiency of lentiviral vector-mediated TGF $\beta 1$ overexpression in $\mathrm{mMSCs}$

The transduction efficiency, which was reflected by the eGFP-positive cell ratio in our study, mediated by the lentiviral vectors after 20 passages was detected by fluorescence microscopy and FCM analysis. The transduction efficiencies of cells overexpressing TGF $\beta 1$ were 82.388.6\% (Fig. 1a, b). TGF $\beta 1$ mRNA levels in mMSCs were detected by qRT-PCR. TGF $\beta 1$ mRNA expression was significantly higher in the mBM-MSC-TGF $\beta 1$ group than in the mBM-MSC-NC group $(p<0.0001)$. However, there was no significant difference between the mBMMSC and mBM-MSC-NC groups ( $p>0.05$, Fig. 1c). Secreted TGF $\beta 1$ levels in the culture media of mMSCs were significantly higher in the mBM-MSC-TGF $\beta 1$ group than in the mBM-MSC-NC group $(p<0.0001$, Fig. 1d). The western blot analysis also showed similar results for TGF $\beta 1$ protein expression in mMSCs (Fig. 1e). Thus, lentivirus-mediated TGF $\beta 1$ transduction was stable and efficient.

In this study, calcium deposition examined by Alizarin Red S staining, lipid accumulation by Oil Red O staining, and polysaccharide accumulation by Alcian blue staining experiment were used to evaluate the multidifferentiation of mMSCs after gene transduction. TGF $\beta 1$ transduction did not change the multip nti 1 differentiation ability of mMSCs (Fig. 2b).

According to FCM analysis, CD29, CD44, d CD10, were positive while CD34 and CD45 were ne ve on mBM-MSC-TGF $\beta 1$, which was in lin with the sarface markers of mBM-MSC (Supplement y Figure 1).

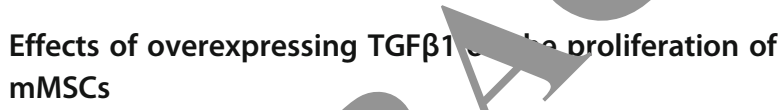
mMSCs

A CCK-8 assay was $\mathrm{u}$ ed evalu the the effects of overexpressing TGF $\beta 1$ or a comparing different growtb curves, as found that overexpression of TGF $\beta 1$ sig ific tly decreased cell proliferation in the mBM-MS TGF $\beta 1$ moup compared to that in the mBM-N SC.NC grou p from days 5 to $7(p<0.05)$. There was no vifica $\mathrm{t}$ difference between the mBM-MSC ara $3 M-n$-NC groups $(p>0.05$, Fig. 2a).

\section{Effec of overexpressing TGF $\beta 1$ on the migration of mMSCs}

The scratch assay and Transwell assay were used to indicate the horizontal and vertical migration abilities of mMSCs. There were no significant differences in the wound areas in the scratch assay among the mBM-MSC, mBM-MSC-NC, and mBM-MSC-TGF $\beta 1$ groups after $12 \mathrm{~h}$ of incubation $(p>0.05$, Fig. $2 \mathrm{c})$. Similar results were also detected in the Transwell assay. No significant differences among the groups were observed $(p>0.05$, Fig. 2d).

\section{Effects of overexpressing TGF $\beta 1$ on the graft retention of mMSCs in the lung after lipopolysaccharide challenge} To track intrapulmonary mMSCs, ex vivo NIR im aging was performed on the lungs at 1,3 , and 7 ays after mMSCs administration. There were no sic icant differences in the fluorescent counts of ROIs amon the groups ( $p>0.05$, Fig. 3a, b).

\section{Mesenchymal stem cells overexpre sing TGF $\beta$ i/nhibited lung inflammation in lipopolysacc ide-induced ARDS} mice

The differentiation of ThI7 an Treg in the lungs of LPS-induced ARDS n was de ected by FCM. At 3 days after mMSCs transpla tion, the number of $\mathrm{CD}^{+}$ $\mathrm{T}$ cells in the lng ncreased significantly in the LPS + mBM-MSC, $\mathrm{L}+\mathrm{MSC}-\mathrm{NC}$, and LPS + mBMMSC-TGF $\beta 1$ gro compared with that in the ARDS group ( $p$ Fig. 4a). Meanwhile, the proportion of Th17 signifizan, $y$ decreased in the LPS + mBM-MSC and LPS + $1 \mathrm{BM}-\mathrm{MSC}-\mathrm{NC}$ groups compared to that in thu RDS group $(p<0.05)$ but significantly increased in the $\mathrm{L} S+\mathrm{mBM}-\mathrm{MSC}-\mathrm{TGF} \beta 1$ group compared to that in $\mathrm{J} P \mathrm{~S}+\mathrm{mBM}-\mathrm{MSC}-\mathrm{NC}$ group $(p<0.05)$ but was still lowver than that in the ARDS group ( $p<0.05$, Fig. $4 \mathrm{~b})$. In addition, the proportion of Treg in the LPS + mBMMSC and LPS + mBM-MSC-NC groups was significantly lower than that in the ARDS group $(p<0.05)$, and the proportion in the LPS + mBM-MSC-TGF 1 group was significantly higher than that in the LPS + mBM-MSCNC group $(p<0.05)$ and even higher than that in the ARDS group $(p<0.05$, Fig. $4 c)$. Moreover, the Th17/ Treg ratio in the LPS + mBM-MSC and LPS + mBMMSC-NC groups was significantly lower than that in the ARDS group $(p<0.05)$, and that in the LPS + mBMMSC-TGF $\beta 1$ group was even lower than that in the LPS + mBM-MSC-NC group ( $p<0.05$, Fig. $4 d$ ).

In addition, similar results were also observed at 7 days after mMSCs transplantation. Compared with that in the lungs of the ARDS group, the number of $\mathrm{CD}^{+} \mathrm{T}$ cells increased significantly in the lungs of the LPS + mBMMSC, LPS + mBM-MSC-NC, and LPS + mBM-MSCTGF $\beta 1$ groups $(p<0.05$, Fig. $5 \mathrm{a})$. At the same time, the proportion of Th17 in the LPS + mBM-MSC and LPS + mBM-MSC-NC groups decreased significantly compared to that in the ARDS group $(p<0.05)$, and the proportion in the LPS + mBM-MSC-TGF $\beta 1$ group decreased further relative to that in the LPS + mBM-MSC-NC group $(p<$ 0.05 , Fig. $5 b)$. In addition, the proportion of Treg in the LPS + mBM-MSC and LPS + mBM-MSC-NC groups was significantly lower than that in the ARDS group $(p<0.05)$, and the proportion in the LPS + mBM-MSC-TGF $\beta 1$ 


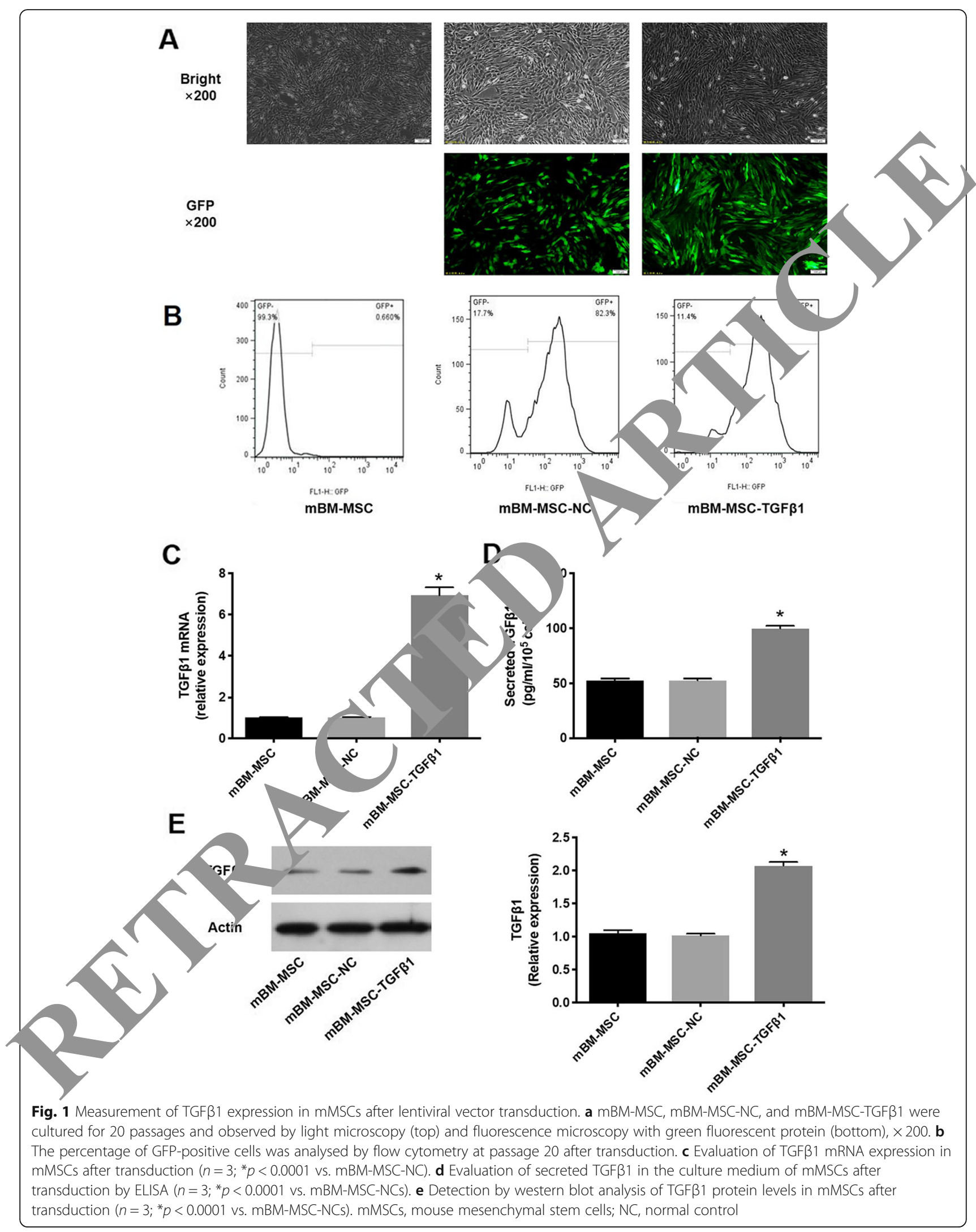




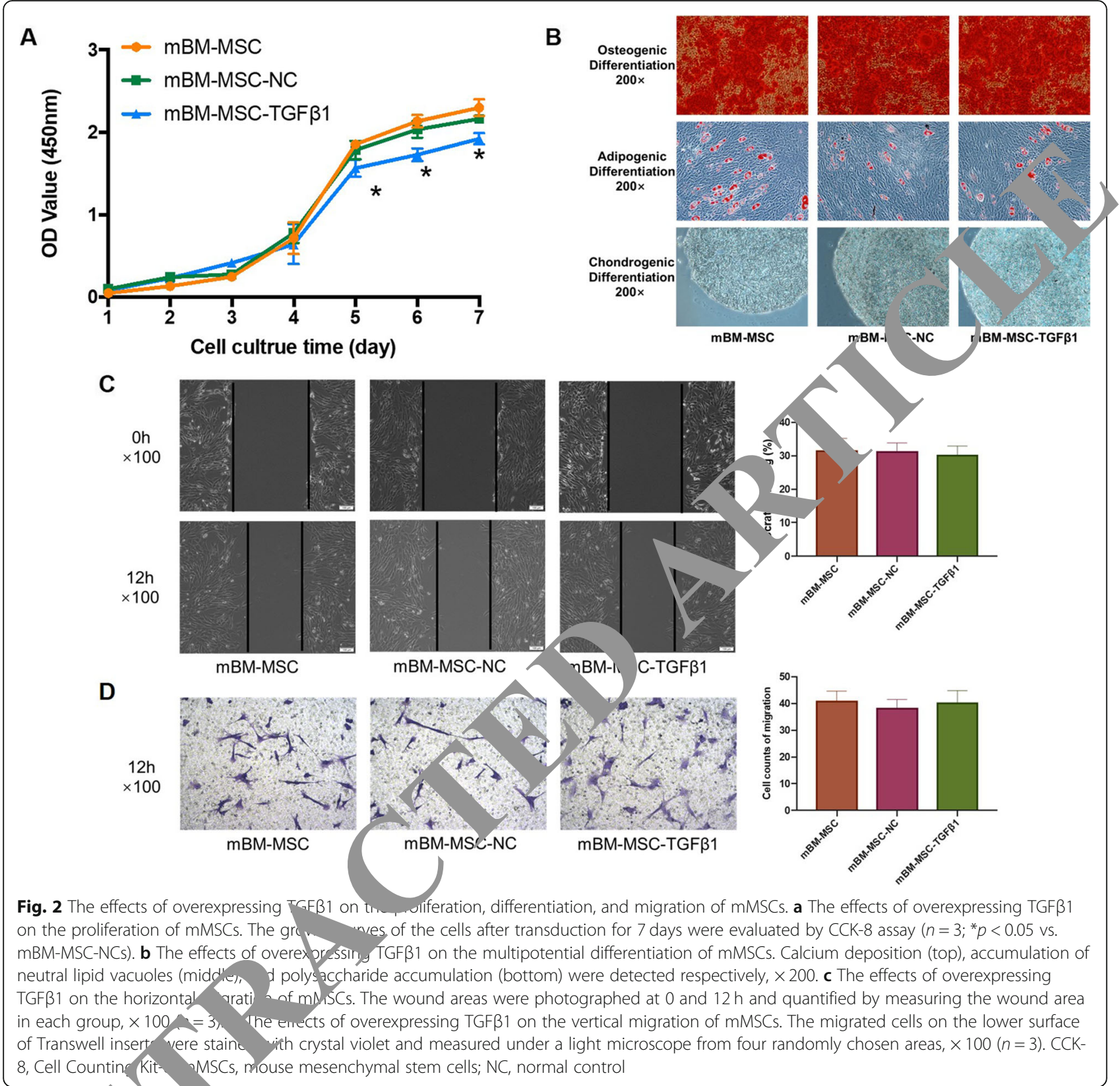

gro was ob ay higher than that in the LPS + mBMTSC JC group $(p<0.05)$ but still lower than that in the A grup ( $p<0.05$, Fig. $5 c)$. The Th17/Treg ratio in the LPS BM-MSC-TGF $\beta 1$ group was significantly lower than that in the LPS + mBM-MSC-NC group $(p<0.05$, Fig. 5d). It was suggested that mMSCs overexpressing TGF $\beta 1$ could further regulate the differentiation of Th17 and Treg and improve the balance of Th17/Treg in the lungs of ARDS mice.

The levels of IL-17A and IL-10 were measured in lung homogenates at 3 and 7 days after mMSCs transplantation by western blot. Compared with that in the
ARDS group, IL-17A content was significantly decreased in the LPS + mBM-MSC and LPS + mBM-MSC-NC groups $(p<0.05)$. mMSCs overexpressing TGF $\beta 1$ further reduced the concentration of IL-17A in the lungs compared with that in the LPS + mBM-MSC-NC group $(p<$ 0.05 , Fig. 6a). Meanwhile, compared with that in the ARDS group, IL-10 content was significantly elevated in the LPS + mBM-MSC and LPS + mBM-MSC-NC groups $(p<0.05)$. mMSCs overexpressing TGF $\beta 1$ could further increase the concentration of IL-10 in the lungs compared with that in the LPS + mBM-MSC-NC group $(p<0.05$, Fig. 6b). It was suggested that mMSCs overexpressing 


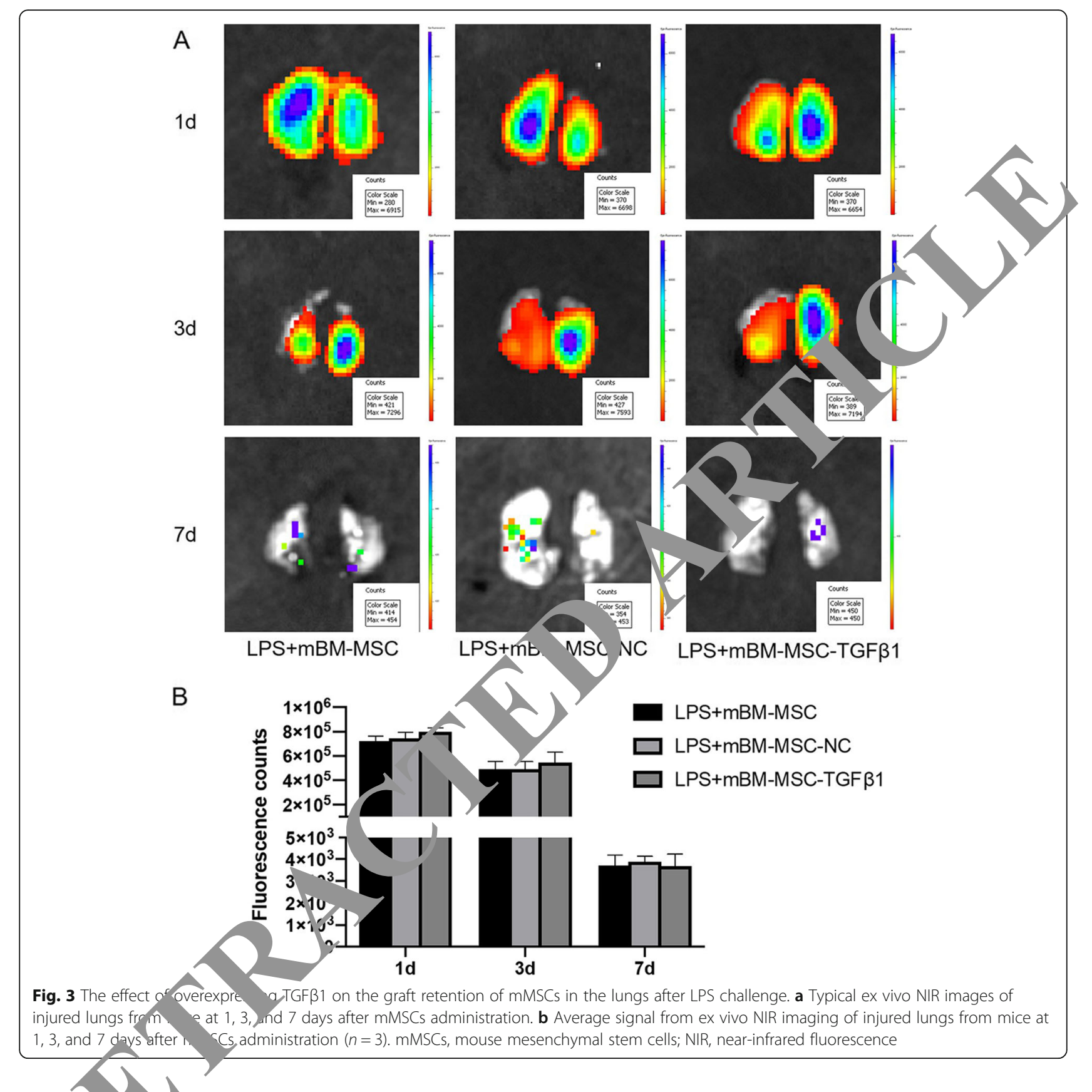

GF couly inhibit the expression of IL-17A while in asmo $1 \mathrm{~L}-10$ levels in the lungs of ARDS mice.

To Trther evaluate the inflammation in the lungs of ARDS mice, proinflammatory cytokines TNF- $\alpha$, IL- $1 \beta$, and IL- 6 concentration in BALF of ARDS mice were also measured using ELISA. The expression of TNF- $\alpha$, IL- $1 \beta$ and IL- 6 in BALF were all significantly elevated in response to the LPS challenge $(p<0.0001)$. The treatment with mBM-MSC-TGF $\beta 1$ statistically decreased TNF- $\alpha$, IL-1 $\beta$, and IL-6 levels than the mBM-MSC-NC did at both 3 and 7 days $(p<0.05$, Supplementary Figure 2A-C).
Overexpression of TGF $\beta 1$ in mesenchymal stem cells improved the lung permeability of ARDS mice

The LWW/BW was calculated to evaluate lung oedema. The LWW/BW was significantly reduced in the LPS + mBM-MSC, LPS + mBM-MSC-NC, and LPS + mBMMSC-TGF $\beta 1$ groups compared with that in the ARDS group at 3 and 7 days $(p<0.05$, Fig. $7 a)$.

To evaluate whether mMSCs overexpressing TGF $\beta 1$ could alter the permeability of the lung, total protein and albumin concentrations in the BALF were measured by mouse-specific ELISAs. The total protein and albumin 


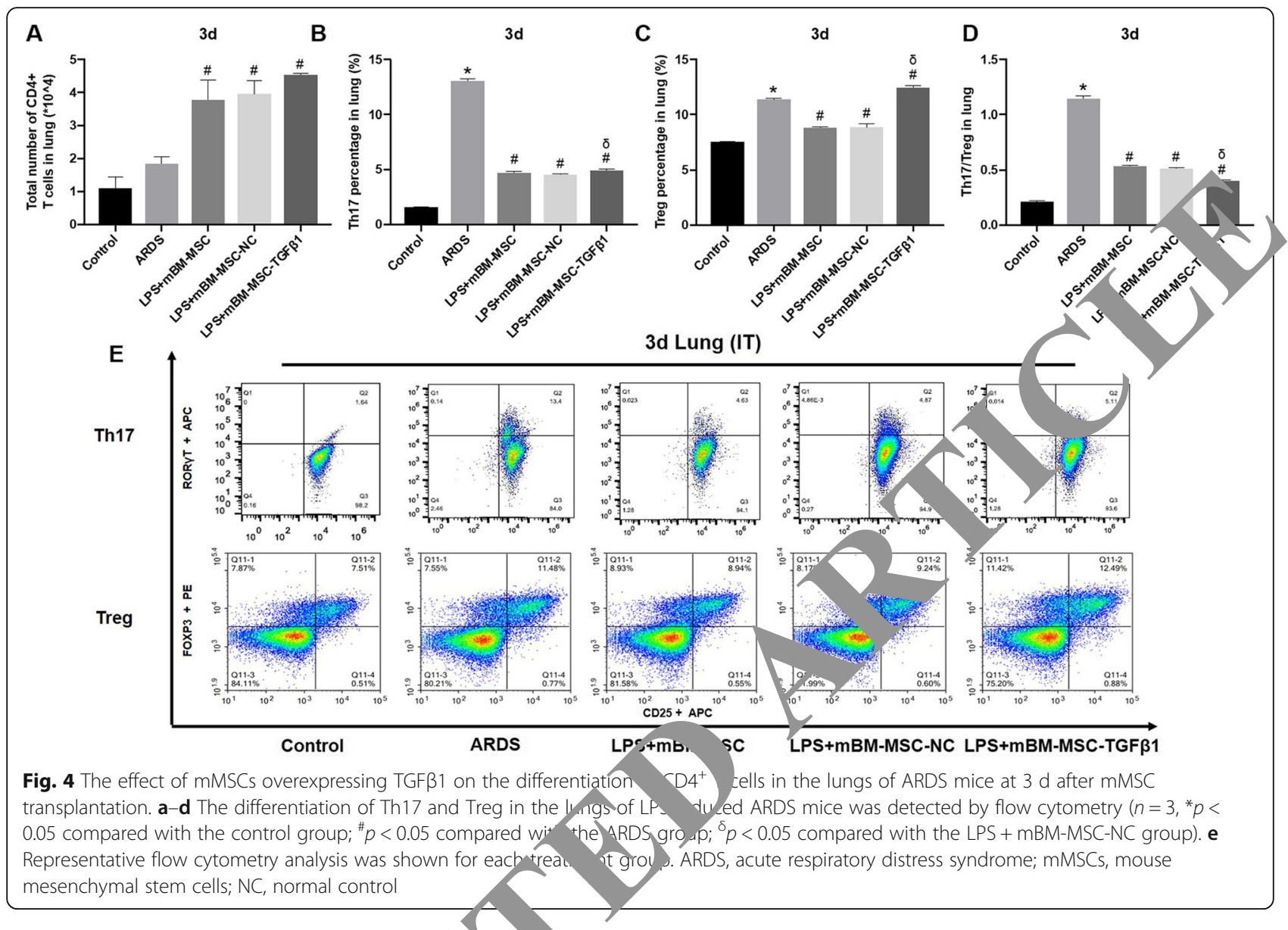

concentrations were significantly re uced in the LPS + mBM-MSC and LPS + mBM-MSC gr oups compared with those in the ARI oroup at both 3 and 7 days $(p<0.05)$. Significant decre in the total protein and albumin conc an wion were also observed in the $\mathrm{LPS}+\mathrm{mBM}-\mathrm{M}=\mathrm{TC} \Omega 1$ group compared with those in the LP $+m$ M 1 -M C-NC group at 3 and 7 days $(p<0.05$, ig. 7 b, c)

Additionally th occludin protein expression level increased significanty in the LPS + mBM-MSC and LPS + n MS C -NC groups compared with that in the ARDC gro $(r<0.05)$. A significant increase was also oser ed ir the LPS + mBM-MSC-TGF $\beta 1$ groups ce oarcu to that in the ARDS group $(p<0.05)$, and the incr $\mathcal{C}$ was much greater than that in the LPS + mBMMSC-NC group $(p<0.05$, Fig. $7 d)$.

Mesenchymal stem cells overexpressing TGF $\beta 1$ improved the pulmonary histopathology of lipopolysaccharideinduced ARDS mice

After LPS-induced lung injury, alveolar wall thickening, alveolar and interstitial inflammatory cell infiltration, haemorrhage, alveolar exudate, and oedema were observed in the lung tissues of ARDS group mice (Fig. 8a), and the Smith score for quantifying lung injury was also increased significantly $(p<0.05$, Fig. $8 \mathrm{~b})$ in the ARDS group. However, compared to those in the ARDS group, histopathologic characteristics and the Smith score were alleviated at 3 and 7 days in the LPS + mBMMSC and LPS + mBM-MSC-NC groups $(p<0.05$, Fig. $8 \mathrm{a}$, b). The effects were greater in the LPS + mBM-MSCTGF $\beta 1$ group than in the LPS + mBM-MSC-NC group $(p<0.05$, Fig. $8 \mathrm{a}, \mathrm{b})$.

\section{Effects of mMSCs overexpressing TGF $\beta 1$ on lung fibrosis in ARDS mice}

To assess lung fibrosis, collagen deposition (which was stained blue) in lung tissue at 7 days after LPS challenge was analysed by Masson's trichrome staining and was markedly increased in the ARDS group compared with that in the control group $(p<0.0001)$. The lung fibrosis score decreased significantly in the LPS + mBM-MSC, LPS + mBM-MSC-NC, and LPS + mBM-MSC-TGF $\beta 1$ groups compared to that in the ARDS group $(p<$ $0.0001)$. Reduced collagen I and $\alpha$-SMA mRNA was also observed after intervention with mBM-MSC, mBM- 


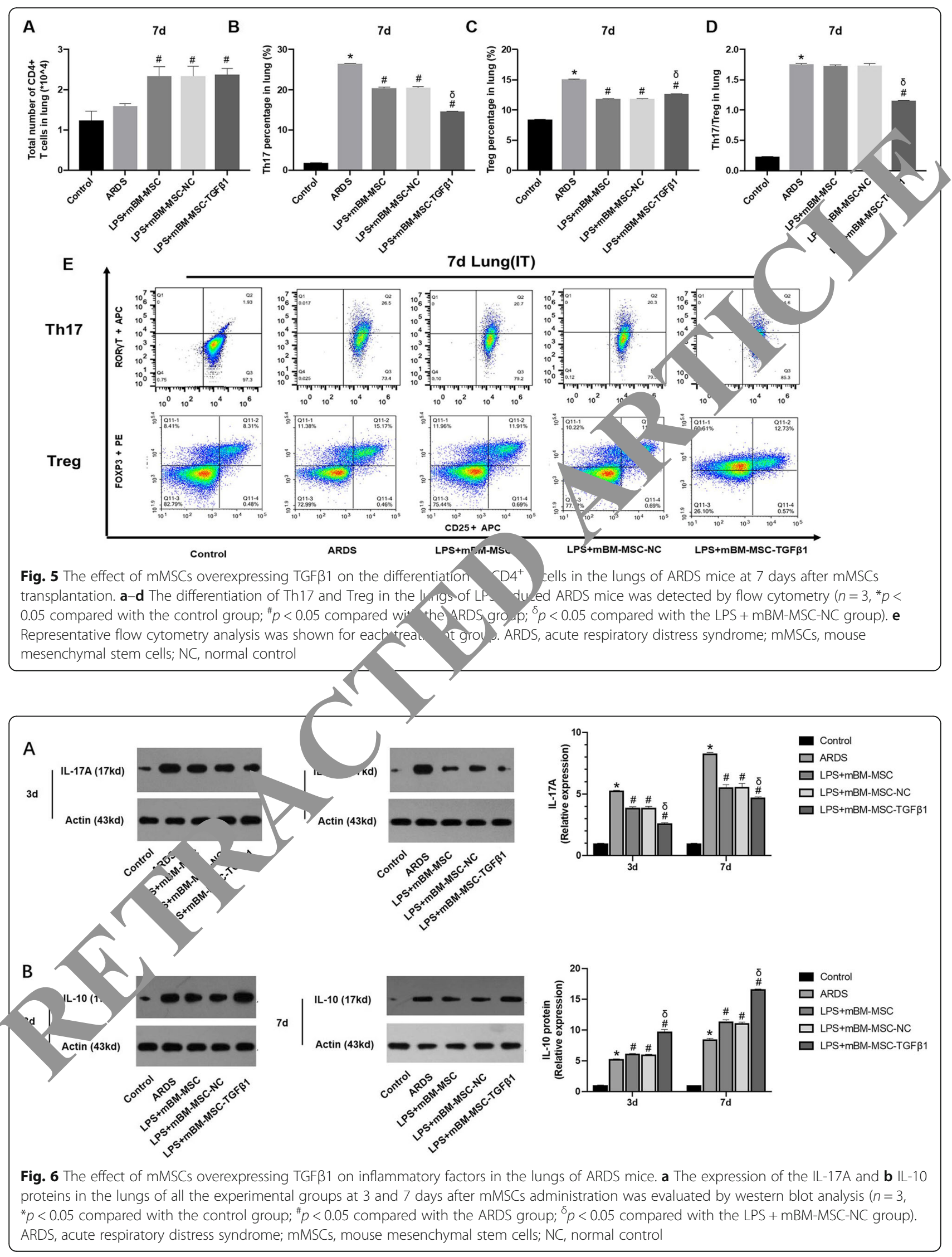




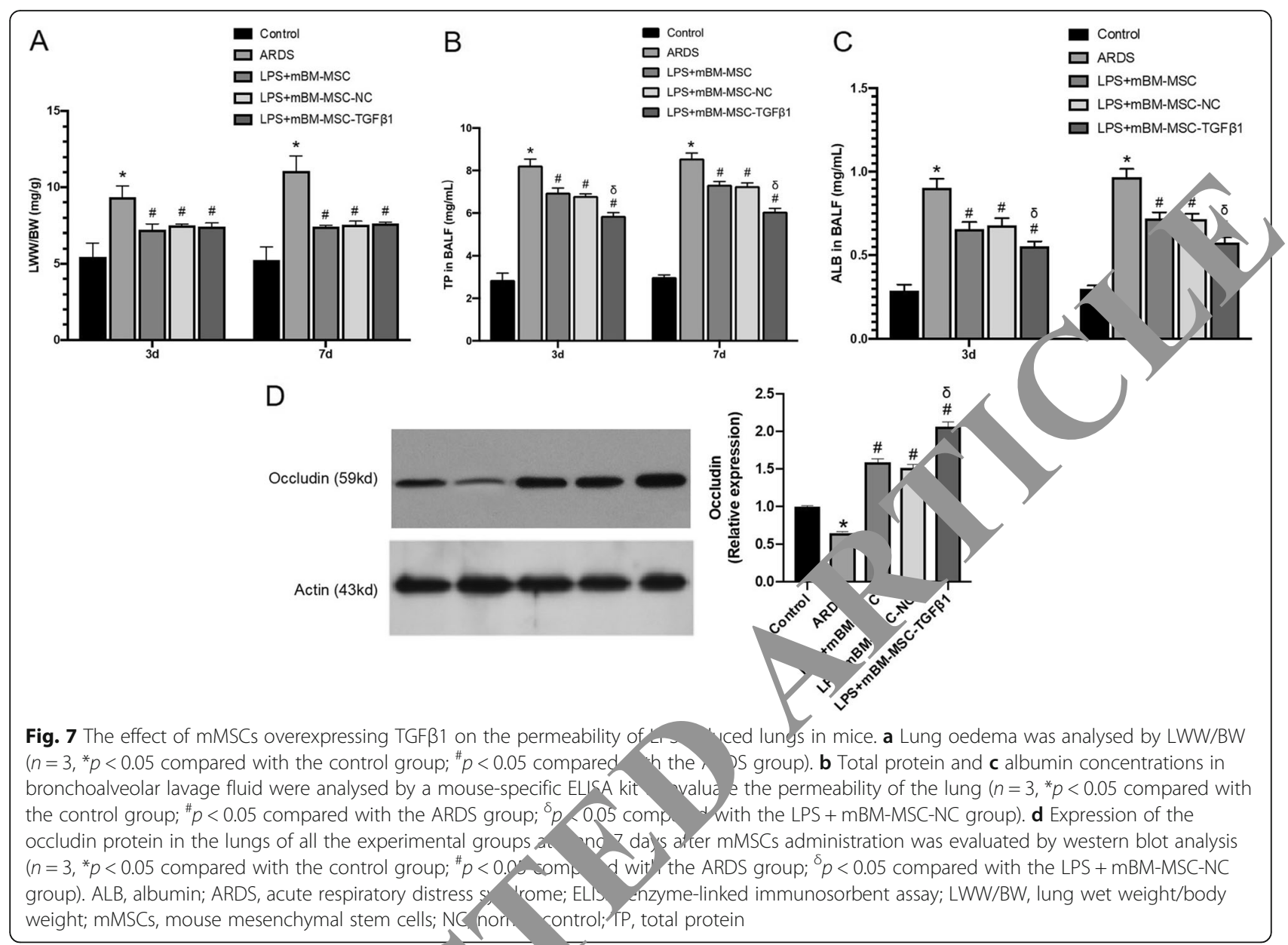

MSC-NC, or mBM-MSC-TGF $\beta 1$ con red vith that in the ARDS group $(p<0.0001$ hut increased $\alpha$-SMA mRNA was found in the IPs BM-MSC-TGF $\beta 1$ group compared with in the LPS + mBM-MSC-NC group $\left(p<0.0001, \mathrm{Fi}_{\mathrm{O}} \mathrm{Oa}-\right.$

\section{Effects of mMS- verexpry sing TGF $\beta 1$ on the survival of ARDS mice}

Mice that received LPS challenge had a significantly decreas the ontro mice $(p<0.05)$. Although there was no onit ant diference in the survival rate in the LPS + n. I-Ivol, LPS + mBM-MSC-NC, and LPS + mBMMSO GF $\beta 1$ groups compared to that in the ARDS group, an upward trend was still found after mMSCs treatment ( $p>0.05$, Fig. 10).

\section{Discussion}

Immunotherapy, one of the important treatments for ARDS, has not made any breakthroughs in the past two decades [18]. A large number of studies have shown that MSCs, multifunctional stem cells with low immunogenicity, could significantly improve the immunity state of ARDS in animal models $[19,20]$. The mechanism is due mainly to the paracrine regulation of cell function and state by a variety of cytokines. TGF $\beta 1$, as a main paracrine cytokine of MSCs, could regulate the systemic immunity state by modulating the differentiation of $\mathrm{T}$ cells in ARDS. In our study, we first constructed mMSCs overexpressing TGF $\beta 1$, and the main findings were as follows. (1) Overexpressing TGF $\beta 1$ inhibited the proliferation of mMSCs during days 5-7 but had no effect on their differentiation or migration. (2) mMSCs overexpressing TGF $\beta 1$ decreased lung permeability and inflammatory cytokine levels and improved the histopathology of lung tissue and in ARDS mice. (3) mMSCs overexpressing TGF $\beta 1$ could significantly modulate the differentiation of T cells into Th17 and Treg while inhibiting the ratio of Th17 and Treg. IL-17A content was also decreased while IL-10 content was increased in the lungs of ARDS mice after treatment with mMSCs overexpressing TGF $\beta 1$. (4) mMSCs overexpressing TGF $\beta 1$ did not aggravate lung fibrosis in ARDS mice.

As an important part of adaptive immunity, $\mathrm{T}$ cell immunity is involved in the development of ARDS [21, 

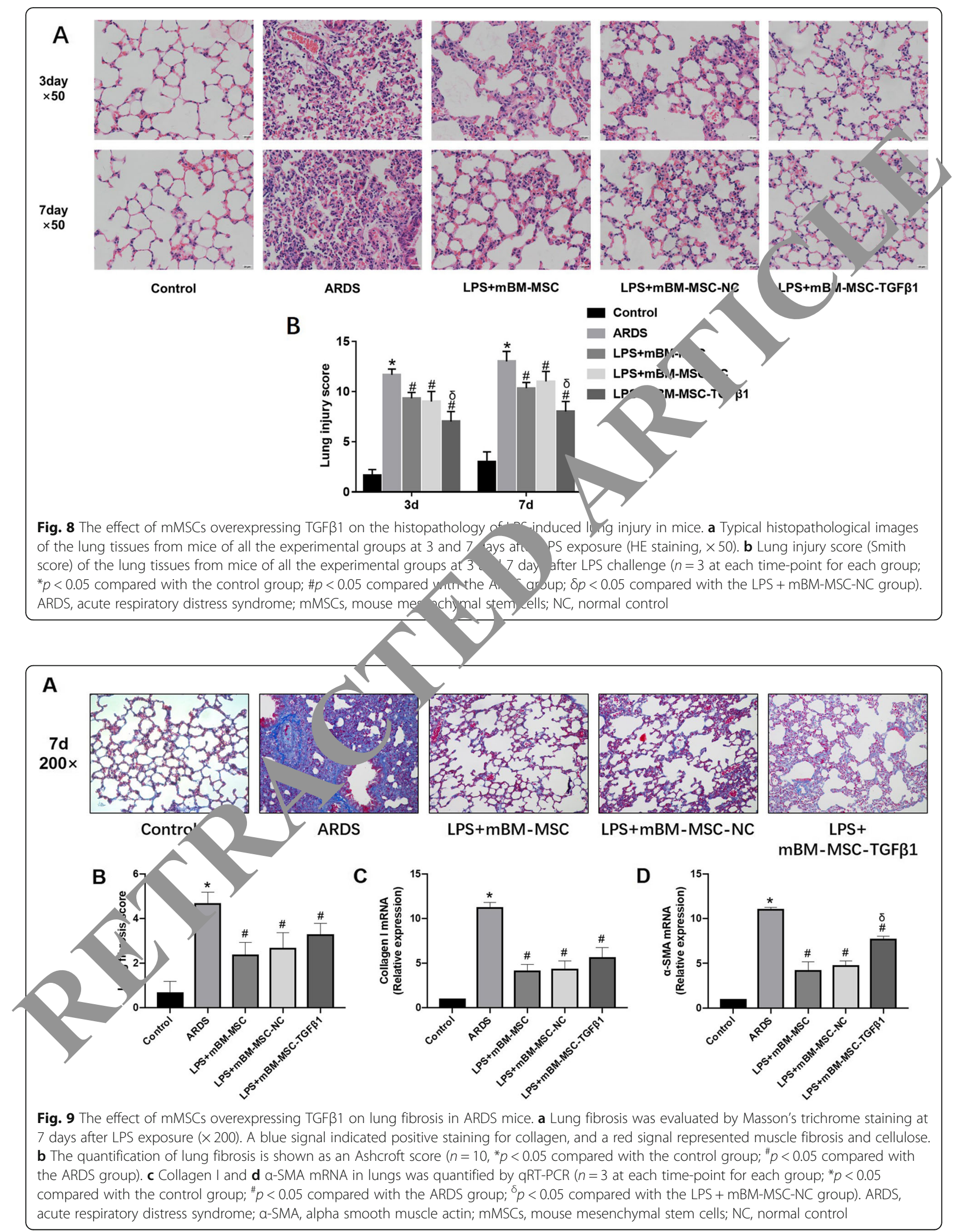


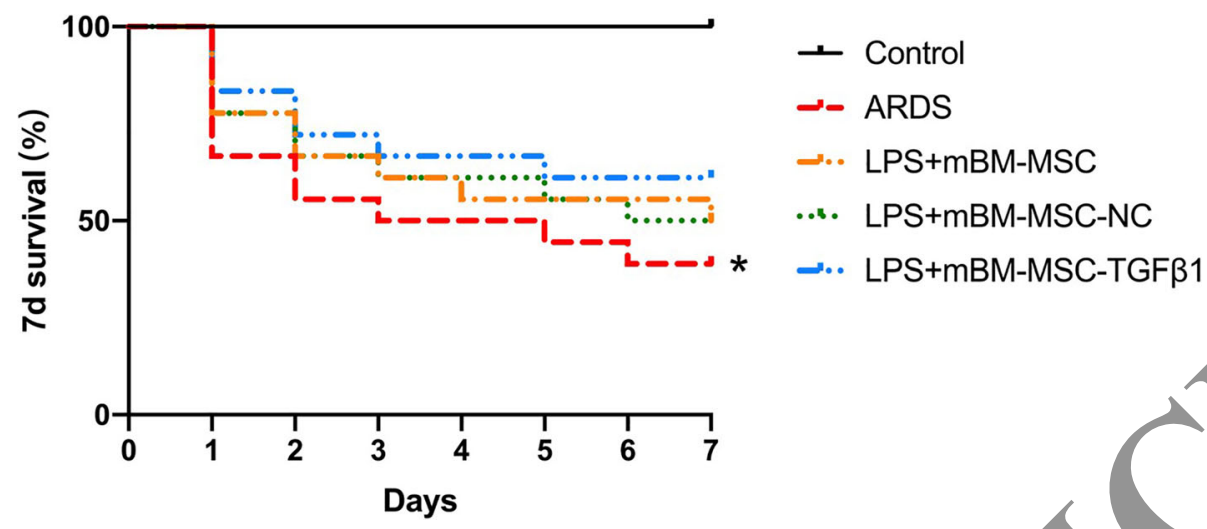

Fig. 10 Kaplan-Meier survival curves. Mice that received LPS challenge in each group were followed for 7 davs a mMsumaministration $(n=$ 18 for each group, ${ }^{*} p<0.05$ compared with the control group)

22]. Several studies have shown that specific regulation of $\mathrm{T}$ cell differentiation could improve the immunity and inflammation state of ARDS in animal models, resulting in prognosis improvement [21, 23, 24]. It was also found in our study that the regulation of $\mathrm{T}$ cell differentiation in patients with community-acquired pneumonia was directly related to their prognosis [25]. Th17 and Tree, as paired $\mathrm{CD}^{+}{ }^{+} \mathrm{T}$ cell subsets, directly contribute to the prognosis of patients with ARDS [9]. At prese th ? regulation of Th17 and Treg differentiation depe "s mainly on antigen-presenting cells, cytokin os nd intra cellular signalling pathways [12]. However, Th $\beta 1$, an important factor regulating $\mathrm{T}$ cell ifferentiatio, had very low expression in MSCs. In ou study, gverexpression of TGF $\beta 1$ in mMSCs by lent "1s tansduction significantly increased TGF $\beta 1$ DNA and protein levels in the cells, as well as in the St/P atant of culture media. However, there no significant effect on the differentiation and rrat of MSCs after transduction. The inhibite a mis ton of mMSCs overexpressing TGF $\beta 1$ may b. lated to re involvement of TGF $\beta 1$ in the differentration $f$ MSCs via cell cycle regulation, which stir needs furt, er study.

In th st dy, the therapeutic effect of MSCs after $\mathrm{TG}^{\mathrm{\Gamma} 0_{1}}$ tr. duction was significantly improved, due ain to the better regulation of $\mathrm{T}$ cell differentiation in KDo nice on day 3 and day 7 and reduced Th17/ Tres atio, thus balancing inflammatory cytokines in vivo. In our previous studies, specific regulation of inflammatory cytokines such as angiotensin-converting enzyme 2 (ACE2) or prostaglandin E2 (PGE2) in MSCs could also improve their therapeutic effects in ARDS animals, which paralleled the results of this study [10, 26]. In addition, a recent study also indicated that MSCs could prevent the differentiation of naive $\mathrm{CD} 4^{+} \mathrm{T}$ cells into Th17, inhibit the production of inflammatory cytokines by 17,1 induce the Treg phenotype in vitro [27]. How er, in our study, the effect of MSCs overexpre TGE $\beta 1$ on $\mathrm{CD}^{+} \mathrm{T}$ cells was mainly to increase the amy unt of Treg without reducing the number of Th1' which may be related to the animal status an etection methods. How to regulate Th17 and Treg differ tiation specifically still needs further study it 0 .

GF $\beta 1$ is also an important index of fibrosis and Inflammation [28]. Despite this, pulmonary fibrosis in ARDS mice was also detected after MSCs transplantation [29]. According to Masson's staining or specific mRNA expression, MSCs overexpressing TGF $\beta 1$ did not significantly increase pulmonary fibrosis in ARDS mice. In addition, our previous study also found that mMSCs could further improve the epithelial injury and pulmonary fibrosis of ARDS mice by increasing differentiation into type II epithelial cells through p130/E2F4 pathway [15], indicating that there might be no side effects related to MSCs transplantation.

This study still has several limitations. First, we induced ARDS by LPS treatment in mice. The murine model of ARDS induced by intratracheal LPS injection focuses only on inflammation in the lungs and cannot fully reflect the complexity of systematic inflammation seen in ARDS patients. Second, MSCs were only administered once intratracheally, and the mice were then sacrificed 3 and 7 days later, which may also not fully reflect the clinical application of such therapeutics; further studies focusing on different routes and doses for MSCs treatment are still needed.

\section{Conclusion}

MSCs overexpressing TGF $\beta 1$ could regulate lung inflammation and attenuate lung injuries by modulating the imbalance of Th17/Treg in the lungs of ARDS mice. 


\section{Supplementary information}

Supplementary information accompanies this paper at https://doi.org/10. 1186/s13287-020-01826-0.

\section{Additional file 1: Supplementary Figure 1. Flow cytometry} identification of mMSCs overexpressing TGF $\beta 1$. Cell surface markers of mMSCs, including CD29, CD44, and CD105 were positive. Additionally, CD34 and CD45 of hematopoietic stem cells were negative. Red lines represent the isotype controls. FSC-A, forward scatter height; mMSCs, mouse mesenchymal stem cells; SSC-A, side scatter height.

Additional file 2: Supplementary Figure 2. Pro-inflammatory cytokines concentrations in bronchoalveolar lavage fluid of ARDS mice. A. TNF-a, B. IL-1 $\beta$ and C. IL-6 were analyzed by mouse specific ELISA to evaluate inflammation in lungs of ARDS mice. $\left(n=3,{ }^{*} p<0.0001 \mathrm{com}-\right.$ pared with the Control group; $\# p<0.05$ compared with the ARDS group; $\delta p<0.05$ compared with the LPS + mBM-MSC-NC group)

Additional file 3.

\section{Abbreviations}

ACE2: Angiotensin-converting enzyme 2; ALB: Albumin; ARDS: Acute respiratory distress syndrome; BALF: Bronchoalveolar lavage fluid; BSD: Blasticidin; CCK-8: Cell counting kit-8; CDS: Coding sequence; DMEM/ F12: Dulbecco's modified Eagle's media/nutrient mixture F-12; EDTA: Trypsinethylenediaminetetraacetic acid; eGFP: Enhanced green fluorescent protein: ELISA: Enzyme-linked immunosorbent assay; FBS: Foetal bovine serum; FCM: Flow cytometry; IL: Interleukin; LPS: Lipopolysaccharide; LWW/BW: Lung wet weight/body weight; mBM-MSCs: Mouse bone marrow-derived mesenchymal stem cells; mBM-MSC-NC: Mouse bone marrow-derived mesenchymal stem cells carrying green fluorescent protein (normal control); mBMMSC-TGF 1 : Mouse bone marrow-derived mesenchymal stem cells carrying TGF 1 ; mMSCs: Mouse mesenchymal stem cells; MOl: Multiplicity of infection; NS: Normal saline; PBS: Phosphate-buffered saline; PGE2: Prostaglandin E2; PVDF: Polyvinylidene difluoride; RIPA: Radioimmunoprecipitation assay buffer; ROls: Regions of interes SD: Standard deviation; SDS-PAGE: Sodium dodecyl sulfate-poly actylamio gel electrophoresis; TBS: Tris-buffered saline; TBST: Tris-buffer aline with Tween-20; TGF $\beta 1$ : Transforming growth factor $\beta 1$; Th17: T relpe cells; TP: Total protein; TNF-a: Tumour necrosis factor-a; Trea ' egulatory els; WT: Wild-type

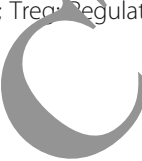

\section{Acknowledgements}

None declared.

\section{Authors' contributions}

CJX participated in the study desond the laboratory work and statistical analysis, prepared draf of the $r$ anuscript, and revised the manuscript according to advic ner authors. ZXW and XM participated in the lab ratory wo, erformed the statistical analysis, and drafted the manusc is JF participe d in the study design and assisted in the statistical analy,is. LL GYY participated in the study design and helped to revise the anuscript. Q. Jere responsible for the study design and revised the manuscript for important intellectual content. All authors read and appro, tr final nanuscript.

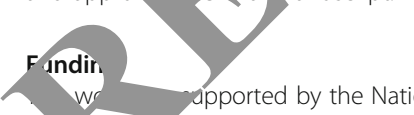

( Natural Science Foundations of Ch. No. 81571874, 81930058), the Postgraduate Research \& Practice Innova YProgram of Jiangsu Province (KYCX17_0168), Jiangsu Provincial Special Program of Medical Science (BE2019749, BE2018743), and National Science and Technology Major Project for Control and Prevention of Major Infectious Diseases of China (2017ZX10103004).

\section{Availability of data and materials}

All data generated or analysed during this study are included in this published article.

Ethics approval and consent to participate Not applicable.

\section{Consent for publication}

All the authors have given final approval of the version to be published and have agreed to be accountable for all aspects of this work.

\section{Competing interests}

The authors declare that they have no competing interests.

Received: 4 March 2020 Revised: 6 July 2020

Accepted: 13 July 2020 Published online: 22 July 2020

References
1. Ashbaugh DG, Bigelow DB, Petty $T L$, et al. Acute rec tory distre s in adults. Lancet. 1967;2:319-23.

2. Rubenfeld GD, Caldwell E, Peabody E, et al acute lung injury. N Engl J Med. 2005;353:1

3. Bellani G, Laffey JG, Pham T, et al. Epidemic ay, pattern of care, and mortality for patients with acute res tory ss svodrome in intensive care units in 50 countries. JAMA 201

4. Thompson BT, Chambers RC, 1 U KD. ACu spiratory distress syndrome. N Engl J Med. 2017;377:562-

5. Martin-Loeches I, Levy $1 M$, A A. Management of severe sepsis: advances, challengmand curre, atus. Drug Des Devel Ther. 2015;9: 2079-88.

6. Ji Y, Zhang W. cel concer Immunol Immuno 2010,5y:979-87.

7. D'Alessin FR, Tsushim Ggarwal NR, et al. CD4+CD25+Foxp3+ Tregs resolve 6 antal lung injury in mice and are present in humans with acute lun inyin _lin Invest. 2009;119:2898-913.

8. Garibaldi B D'Alessio FR, Mock JR, et al. Regulatory T cells reduce acute lung injury t'roproliferation by decreasing fibrocyte recruitment. Am J vir Cell Mol Biol. 2013;48:35-43.

X, Ji MS, Yan J, et al. The ratio of Th17/Treg cells as a risk indicator in acute respiratory distress syndrome. Critical care (London). 2015;19:82. $H$, Liu L, Chen Q, et al. Mesenchymal stem cells overexpressing angiotensin-converting enzyme 2 rescue lipopolysaccharide-induced lung injury. Cell Transplant. 2015;24:1699-715.

11. Luz-Crawford P, Kurte M, Bravo-Alegria J, et al. Mesenchymal stem cells generate a CD4+CD25+Foxp3+ regulatory T cell population during the differentiation process of Th1 and Th17 cells. Stem Cell Res Ther. 2013;4:65.

12. Chen W, Konkel JE. Development of thymic Foxp3(+) regulatory T cells: TGF-beta matters. Eur J Immunol. 2015;45:958-65.

13. Zhang X, Chen J, Liu A, et al. Stable overexpression of p130/E2F4 affects the multipotential abilities of bone-marrow-derived mesenchymal stem cells. J Cell Physiol. 2018;233:9739-49.

14. Xu XP, Huang LL, Hu SL, et al. Genetic modification of mesenchymal stem cells overexpressing angiotensin II type 2 receptor increases cell migration to injured lung in LPS-induced acute lung injury mice. Stem Cells Transl Med. 2018:7:721-30.

15. Zhang X, Chen J, Xue M, et al. Overexpressing p130/E2F4 in mesenchymal stem cells facilitates the repair of injured alveolar epithelial cells in LPSinduced ARDS mice. Stem Cell Res Ther. 2019;10:74.

16. Kramer BW, Joshi SN, Moss TJ, et al. Endotoxin-induced maturation of monocytes in preterm fetal sheep lung. Am J Physiol Lung Cell Mol Physiol. 2007;293:L345-53.

17. Cai SX, Liu AR, Chen S, et al. Activation of Wnt/beta-catenin signalling promotes mesenchymal stem cells to repair injured alveolar epithelium induced by lipopolysaccharide in mice. Stem Cell Res Ther. 2015;6:65.

18. Martin GS, Mannino DM, Eaton S, et al. The epidemiology of sepsis in the United States from 1979 through 2000. N Engl J Med. 2003;348:1546-54.

19. Cardenes N, Caceres E, Romagnoli M, et al. Mesenchymal stem cells: a promising therapy for the acute respiratory distress syndrome. Respiration. 2013;85:267-78.

20. Bassi EJ, de Almeida DC, Moraes-Vieira PM, et al. Exploring the role of soluble factors associated with immune regulatory properties of mesenchymal stem cells. Stem Cell Rev Rep. 2012;8:329-42.

21. Lomas-Neira J, Monaghan SF, Huang X, et al. Novel role for PD-1:PD-L1 as mediator of pulmonary vascular endothelial cell functions in pathogenesis of indirect ARDS in mice. Front Immunol. 2018;9:3030.

22. Tan W, Zhang C, Liu J, et al. Regulatory T-cells promote pulmonary repair by modulating $T$ helper cell immune responses in lipopolysaccharide-induced acute respiratory distress syndrome. Immunology. 2019;157:151-62. 
23. Li Q, Hu X, Sun R, et al. Resolution acute respiratory distress syndrome through reversing the imbalance of Treg/Th17 by targeting the CAMP signaling pathway. Mol Med Rep. 2016;14:343-8.

24. Claser C, Nquee SYT, Balachander A, et al. Lung endothelial cell antigen cross-presentation to CD8(+)T cells drives malaria-associated lung injury. Nat Commun. 2019;10:4241.

25. Xue M, Xie J, Liu L, et al. Early and dynamic alterations of Th2/Th1 in previously immunocompetent patients with community-acquired severe sepsis: a prospective observational study. J Transl Med. 2019;17:57.

26. Lu X, Han J, Xu X, et al. PGE2 promotes the migration of mesenchymal stem cells through the activation of FAK and ERK1/2 pathway. Stem Cells Int. 2017;2017:8178643.

27. Zhang S, Chen X, Devshilt I, et al. Fennel main constituent, transanethole treatment against LPSinduced acute lung injury by regulation of Th17/Treg function. Mol Med Rep. 2018:18:1369-76.

28. Wu H, Yu Y, Huang $H$, et al. Progressive pulmonary fibrosis is caused by elevated mechanical tension on alveolar stem cells. Cell. 2020:180:1-15.

29. Islam D, Huang Y, Fanelli V, et al. Identification and modulation of microenvironment is crucial for effective mesenchymal stromal cell therapy in acute lung injury. Am J Respir Crit Care Med. 2019;199:1214-24.

\section{Publisher's Note}

Springer Nature remains neutral with regard to jurisdictional claims in published maps and institutional affiliations.
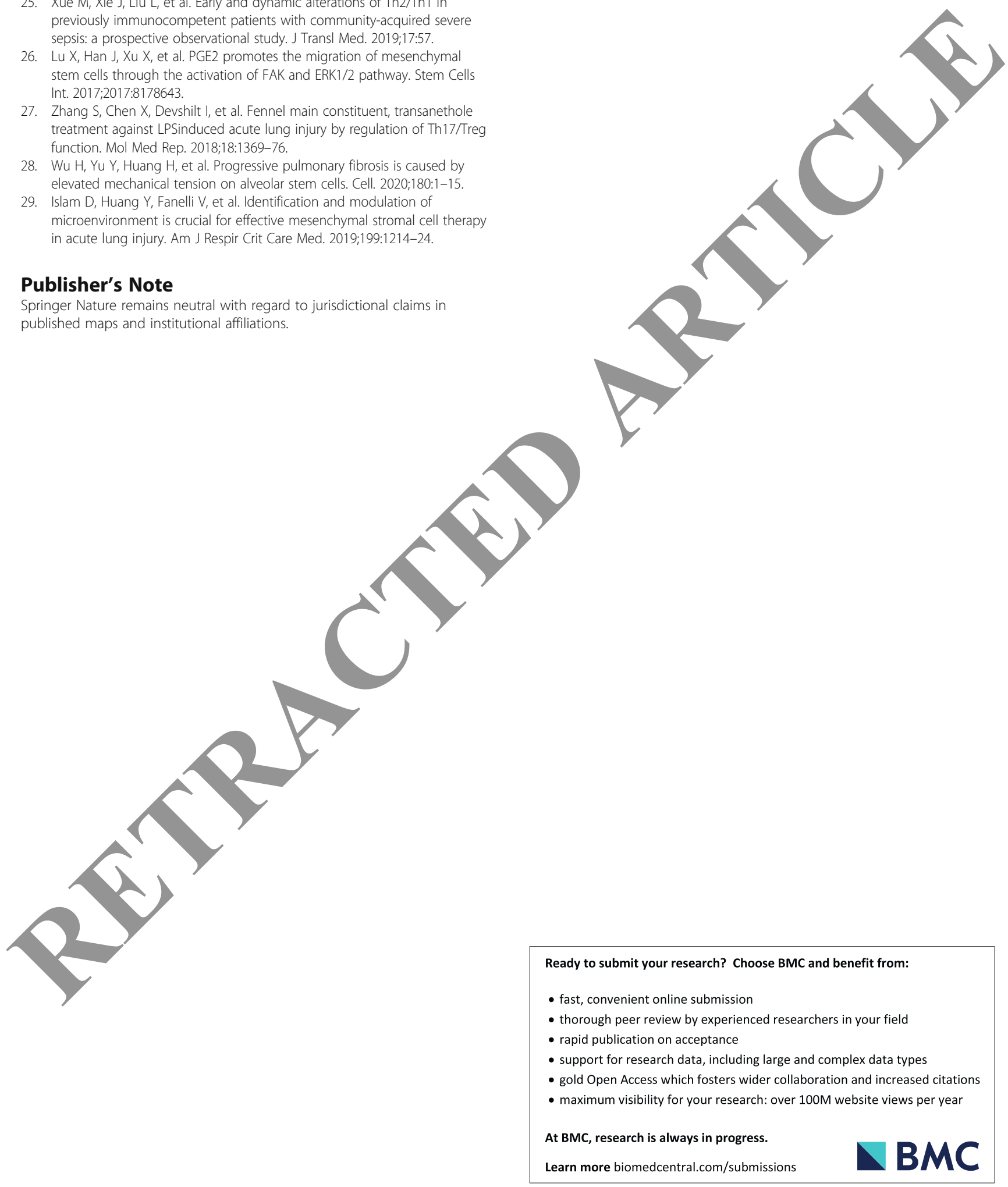